\title{
Terrenos - Cantos pra Empestar o Latifúndio do Conhecimento
}

\section{Terrain - Chanting to plague knowledge's soil}

\author{
Dora Moreira Barreto \\ Cavalcante \\ Doutoranda no Programa \\ Interdisciplinar de Linguística \\ Aplicada da Universidade \\ Federal do Rio de Janeiro, mestra \\ em estudos contemporâneos das \\ artes pela Universidade Federal \\ Fluminense \\ dora@guara.art.br \\ https://orcid.org/0000-0002- \\ 5735-5940
}

\section{Ana Aline Furtado \\ analine.furtado@gmail.com}

Recebido em:11/10/2020

Aceito em:31/03/2021

\section{Resumo}

O presente artigo traz experimentos de escritas calcados em submetodologias e sublínguas a fim de propor desmantelamentos do edifício dos saberes ocidentais hegemônicos que constituem as bases da academia como a conhecemos.

Palavras-chaves: epistemologia, linguagem, fim de mundo

\section{Abstract}

This article brings experiments of writing based on submetodologies and sub-languages in order to propose dismantling on the building of hegemonic western knowledge that constitute the bases of the academy as we know it.

Keywords: epistemology, language, apocalypse 
sobrevivência não é uma habilidade acadêmica

Audre Lorde

mas dos povos invadidos, expropriados da terra

Quando eu vejo uma onça perto do meu terreiro, eu tenho cautela... Eu vou observar... e vou fazer duas perguntas... vou me perguntar se ela tá com fome... Se tiver, eu vou alimentar. E vou me perguntar, será se ela foi adestrada? Antônio Bispo

Quem é você no terreiro com a onça? A onça? O terreiro? A pessoa que está a enxergar a onça? Olhar para as relações e sair da fixidade, isso tem feito há muito tempo os povos originários, as comunidades continuadoras de quilombo, as comunidades ribeirinhas, as comunidades de pesca, as favelas, o resto do mundo fora da norma, coletivizad_s ou não. Num evento online - habitar a terra, fruir a vida - foi perguntado a Antônio Bispo sobre a aliança entre pessoas não racializadas e pessoas racializadas, à qual ele respondeu com a história da onça. Cá estamos as duas, a conversar sobre as questões que nos atravessam acerca da produção de saberes no mundo assimétrico. Uma mulher branca e uma mulher negra, sem romancear, apenas tentando. Aqui não é terreno seguro. Não é terreno sem contexto. Não é terreno sem luta. Terreno baldio não cumpre função social, é especulação. Ter espaço para enfrentar, ter espaço para discordar. Como mulher negra, quero marcar quem diz o quê. Em forma de diálogo, falaremos por nós cada uma. Fui convidada a estar aqui, a pensar junto e a escrever junto, não sei como isso se concretiza, mas o meu compromisso é com o olhar até mudar, mudar para não querer dominar. Dito isso, pergunto:

como construir confiança? há confiança na assimetria de poder? a mulher branca traz memória de um quando:

Era uma espécie de minicurso da Jota Mombaça, na casa 24, que em 2016 ficava no Rio de Janeiro, perto da Lapa. Logo depois de uma das participantes afirmar que, no âmbito das pesquisas acadêmicas e das distâncias entre sujeito pesquisador e objeto de pesquisa a gente não diminui assimetria, a gente produz apagamentos, a professora perguntou: Como, então, trabalhar contra as assimetrias sem produzir apagamento?

Quando leio essa pergunta, penso que não é um possível. Não agora. E saber da impossibilidade não isenta ninguém de continuar lutando contra as assimetrias de poder. Afinal, como enuncia Octávia E. Butler, n’A Parábola do Semeador (BUTLER, 2018, p.120) "todas as lutas são essencialmente Lutas por poder. Quem governará, quem liderará, quem definirá, refinará, confinará, criará, quem dominará.” Então, penso que dentro de estruturas assimétricas, sempre haverá quem pode definir, e quem pode ser apagado de seu gesto acional. Por todos os meios necessários. Se pegarmos a definição de Latifúndio, por exemplo, chegaremos a questões pertinentes de como a terra foi explorada nos últimos 500 anos e de como a improdutividade dessas vastas áreas, somadas à exploração de mão de obra escravizada estruturam os modos relacionais de dominação.

Eu tava partilhando uma tentativa de recusa em tomar outras vidas e corpos como objeto de pesquisa. Quando a conversa começou a girar entre três ou quatro pessoas, ela começou a levar a pauta pra outro canto, perguntando como tinha sido os dias de encontro praquelas pessoas que estavam ali. Foi bem quando ouvi de uma das pessoas que aquela tarde tinha sido bem inútil, porque ela, que tava tentando encontrar sentido em estar numa graduação que em nada conversa com sua vida, saiu de casa pra ouvir um monte de gente privilegiada acadêmica reclamar dos seus privilégios. Não foi a primeira nem a última vez que ela 
foi tão generosa em nos situar no rolê. Esta escrita é parte de uma tese, mas se escreve no fundamento dum conjuro. Esse conjuro parte de dar fé que o projeto colonial em cada um_de nós opera - operamos - contra o desmantelamento das assimetrias na perpetuação dos apagamentos. Esse conjuro anda pelas brechas, arriscando caminhos de desmantelar essa dualidade sem maquear as assimetrias.

O trabalho da consciência mestiza é o de desmontar a dualidade sujeitoobjeto que a mantém prisioneira, e o de mostrar na carne e através de imagens no seu trabalho como a dualidade pode ser transcendida [...] sou um ato de juntar e unir que não apenas produz uma criatura tanto da luz como da escuridão, mas também uma criatura que questiona as definições de luz e de escuro e dá-lhes novos significados. (ANZALDÚA, 2005, p. 707)

Pra finalizar a oficina, Jota Mombaça riscou no chão do terreiro da Casa 24 um quadrado escrito Lugar de Fala, e no espaço fora do quadrado o dizer Lugar de Cala. Eram os últimos instantes daquela encontra e a proposta era que quem quisesse partilhar o que havia escrito no exercício anterior, ou mesmo dizer qualquer coisa, caminhasse até o quadrado pra falar. Que eu me lembre, aquela foi a primeira vez que não falei em uma roda pública 'aberta' à fala, tamanha a dificuldade, na época, de pensar que minha fala era, sim, situada.

Eu dou o maior valor à palavra. Gosto quando a vibração dela toca meu corpo e meu pêlo e às vezes eu queria mesmo era sentir o cheiro da palavra. Gosto principalmente dos seus sons, gosto dos sons que a gente faz quando tá desdizendo a palavra deles. Quando troca o $s$ pelo $r$, ou mermo quando a gente tira o $s$ do plural e assume que qualquer palavra já é uma ruma. Eu gosto dessa história de escutar os dizer das gentes. Eu demorei foi muito, sabe, pra escutar minha voz. Acho que por isso eu falava, falava, falava, escrevia, escrevia, escrevia e não funcionava, nao dava, pq eu não tava mermo escutando. Então, pra mim, era mesmo que eu não tivesse falando. E quando eu digo que eu demorei muito, talvez nem seja essa demora toda, pq tem um tempo entre o dar fé e o dar conta. Quando eu percebo, quando eu quero, quando eu digo que eu vou, eu já comecei. Não na metafisica de que querer ja é poder, já é começar, mas porque tem um tempo que as coisas ficam vibrando no corpo, um trabalho que a gente já vai fazendo, até a gente conseguir dar conta de materializar. Inclusive porque pra falar, escrever e se escutar, a gente precisa se mergulhar nos muitos indizíveis, trocar a pele dessa escrita culta que tanto engasga, tanto prende a língua. Acho que é isso, essa norma que faz a gente falar desmedidamente, uma ruma de palavra, uma atrás da outra, porque nenhuma delas se achega no que a gente precisa conjurar e repartir aqui. Eu gosto quando Gabriela Barreto (2020) diz que tava "materializando uma tese que já foi escrita". Eu escuto e me vem logo essa parte muito complicada da produção de uma tese, em que parece que tudo já tá pensado e elaborado na nossa cabeça, em que as coisas tão vividas e sentidas, mas que a gente olha pro papel e as palavras ali não tão nem longe de chegar perto de dizer. É uma hora em que nem as nossas dão conta do que a gente queria tar dizendo, do que a gente sabe que pode mover. É esquisito porque parece que você precisa fazer um trabalho que já fez, e você não tem garantia de que dessa vez vai, e de que você não vai precisar fazer de novo. Muito pelo contrário, é sobre fazer, desmanchar e refazer. Nessas horas, parece que não dá nem pra estar com as suas gentes. Aí a gente foca no conjuro, que é bem aí nesse momento que as gentes que leio são mais preciosas pra esta escrita. É exatamente aí que a revisão bibliográfica deixa radicalmente de ser um aparato para legitimação dentro da academia e ganha corpo a proposta de tentar fazer aliança com os textos e autor_s que vão costurando a pesquisa. Aliança que eu digo aqui, é sobre deixar de lado a inundação de si, que é das maiores armadilhas da cisbranquice em uma escrita implicada. Já somos tão viciadas em nossas subjetividades, de um lado, e estamos tão à sombra da aprovação da cisbranquice masculina, de outro, que nos dias de hoje não perdemos uma chance de expor mais e mais de nós, não importando a quem essa exposição possa calar, que violências possa perpetuar. É preciso, aqui, um trabalho quântico de distinção.

É assim, inclusive, que busco aqui me aliar a uma bibliografia prioritariamente dissidente de gênero, de sexualidade e de raça. Porque elas me inundam, me dando pistas para sair do jogo do eco/ego em que me enredo com o consenso branco (KILOMBA, 2019b). É também porque são el_s que trazem as perspectivas dos mundos que esta escrita conjura. Me ensinam o fim deste mundo ainda que eu precise queimar com 
ele. Me ensinam a só ser, e que não tem nada em mim pra queimar com esse mundo de que eu possa me ressentir que arda mais que o que esse mundo já rasgou nas gentes. É assim que essa bibliografia se compôs d_s escritor_s que é feita. Aqui, só posso falar desde onde busco aliar-me a el_s. E como esta escrita é sobre abandonar os extrativismos, que extração não é aliança, tem aqui uma investigação de formas, desmantelamentos e experimentações para que eu tenha para trocar nessa aliança, para que daqui também tenha - no sentido que os povos originários, quilombolas e ribeirinhos dão ao termo - para estas lutas, vidas e escritas, o que ser extraído.

Porque também é importante a gente conseguir dar algum nome que não deixe tudo tão vago. A gente dá nome pra gente conseguir mover um pouco mais. Só porque a gente ainda não tá com a telepatia tão afiada quanto a gente sente. Então também como as estruturas que tem são as estruturas cisbrancas, a gente vai tentar dançar com elas também, a muito contragosto. Mas dançando que nem capoeira, pra dar rasteira. O negócio é que a gente vai dançando a contragosto, mas as vezes quando a gente dá fé a gente tá achando bom, aí é a armadilha do babado. A gente precisa é ver que mesmo na dança deles, a gente não precisa se apegar nas ferramentas deles pra fazer nossas coisas, porque as coisas da gente não se tecem das ferramentas deles. O esquisito é que quando eu falo deles, eu to falando minhas também, né. Porque esse eles tá bem vivim aqui dentro de mim. E esse trabalho de destruir o eles em mim sem me distruir é uma conta que nem sempre fecha. Quase nunca. Por isso que a escrita de uma tese dessas tem que se fazer de outras equações, outras contas, outros números. Aí às vezes eu até consigo matar mais eles em mim, aí eu fico até felizinha. Quer dizer, eu fico meio vazia na hora. Eu vou ficando felizinha quando eu vou vendo as coisas que cabem no espaço que essa morte abriu. Essa escrita, ela é pra isso. A gente escreve pra abrir espaço, abrir porteira.

$\mathrm{E}$ às vezes a gente faz as coisas existirem mesmo sem materializar, né? Mas a gente precisa materializar porque a gente tá é aqui, na materialidade. E porque é com a matéria também, com as partículas quânticas, materializando nosso poder - esse poder de outra coisa -, que a gente atravessa os tempos, que a gente deixa os tempos atravessar a gente. Deixa não, que o tempo não pede nossa permissão, ele atravessa e pronto. Mas é.. que a gente se conecta. Nessas escritas eu tenho aprendido que eu não corro mais contra o tempo, não, é o tempo que corre comigo. Essa escrita tem um tempo, sabe, o tempo tem ela. E nesse tempo não tem um cronograma, não tem uma data de revisão bibliográfica, uma data de campo, que aí depois a gente senta, analisa dado, faz pesquisa. É enlinhado mesmo, entramelado. Acho que porque essa coisa de trabalhar contra a assimetria sem perpetuar apagamento carece que a escrita não seja mais toda guiada pela razão e que o conhecimento não seja mais sobre o tempo da produtividade. É essa conversa toda de descolonização.

É... porque as coisa que eu tenho que ler, elas vão vindo na medida que eu vou vivendo as coisas que eu preciso sentir pra poder escrever essa tese. E os encontros, as conversas, eles vão na frente. E as leituras também vão noutra frente, puxando eles. É enlinhado mesmo e tem a ver com a espiral de Lêda Maria Martins (2002). Quando eu falo $a$ gente, não é porque é unidade, é porque eu to invocando todo mundo que tá comigo. Mas acho que cada um_ escreve pruma coisa. É sobre isso, imagine aí uma academia onde cada um_ pudesse escrever pruma coisa, com uma coisa. Aquela coisa mesmo que a pessoa queria escrever. Aquilo que bota a pessoa pra dormir, que bota a pessoa pra acordar, que tira o juizo, sabe? Que tira a paz e que quando a pessoa faz traz a paz de novo e quando ela revisita, a paz escapuliu. Imagine se cada um_ pudesse escrever sobre isso, escrever disso, sem ter que ficar pedindo autorização, se justificando. Se a gente pudesse ter uma academia onde a gente exercitasse o que cada corpo pede, e aí a gente ia se encontrar. Pode parecer que cada um_ia fazer uma coisa, que ia ficar muito individual, mas num é, no avesso, a gente ia era se encontrar mesmo, se ajuntar mesmo, cada um_com o pedacinho de coisa que tem pra ofertar pr_s outr_s.

Eu to criando coragem de falar, né. É engraçado porque eu sempre falei muito, mas agora, eu to criando coragem de falar as coisas que eu escuto. E é muito diferente. Já me agoniava muito essa coisa de ter que escrever demais, ter que falar demais, aparecer demais. Porque eu não me via, né. Eu não me enxergava, nem escutava. Ficava só ali encantada comigo mesma sem nem saber o que era, Narcisa. Eu não me lia. Quando eu digo que eu não me lia, não é que eu não pegasse meu texto pra ler. Quando eu digo que eu não me enxergava, não é que eu não ficasse em frente os reflexos. É que eu não me contaminava de outros olhares pra 
me enxergar. Eu botava essa ruma de palavra, essa ruma de coisa justamente pra não enxergar. Tanto que eu falava muito rápido, que era pra não ter silêncio no meio das coisas. Aí, agora que eu escuto, eu percebo que eu vou abandonado as ideias pelo meio do caminho. Mas eu não tô abandonando, não, quando a espiral passar de novo, a gente encontra de novo com elas. Aí, falando nela, eu queria falar de novo: imagina se a gente tivesse uma academia. Num ia ser academia o nome, né, pra começar. Mas imagina, se a gente pudesse escrever o que é da gente. Aí quem quisesse ia ler, ia estudar tudo misturado tudo entramelado, que nem é. Quem gostasse ia poder começar que nem eu faço aqui, que eu começo um parágrafo, aí vem uma ideia que cabe em outro canto, aí eu boto lá em outro canto e depois quando eu volto pra cá eu já ligo com outra ideia, aí quando eu vejo eu escrevi dez páginas num canto que num tinha nada haver, mas é tudo virando texto. Ou podia ser doutro jeito também, do jeito que fosse o jeito da pessoa.

Nesta escrita, quem vai na frente é o texto. Eu deixo ele ir guiando, palavra por palavra, como se eu que fosse dele. Se eu fico tentando dar ordem, os dedos desobedecem, atuleimados. Aí é do texto mesmo que eu vou tirando a estrutura, é ele quem se reparte em estilhaços entramelados que vão sendo escritos em tempo espiralado. Essa coisa de escrever é muito doida, né? Porque primeiro eu preciso colocar pra fora, vomitar palavra, artigo, letra.

Depois chega um tempo que não dá nem pra olhar pra cara delas. Aí quando vai chegando os prazos, e eu ainda não conseguindo nem olhar, tão longe que a gente fica de tudo que já botou pra fora. Parecia é que eu não sabia de nada do que vive nessas páginas aqui. Mas aí de tanto aperreio e tanto matutar, tal hora eu to aqui, de novo, toda íntima, fazendo texto. Relação, encontro, parece mesmo que requer é distância, né? Agora, eu quis escrever que comecei com uma oração que pedia licença, Ago, mas essa escrita só existe sendo toda licença e toda oração. Ou melhor, "O texto é uma praga que a gente roga no mundo esperando que alguém leia e passe o feitiço adiante" (PANAMBY, 2016, p. 10).

Em uma conversa com Conceição Evaristo, na Livraria da Travessa, mulheres contavam relatos das leituras de suas obras, cada qual acabando toda vida trazendo uma história de si. Aí a autora disse que ficou se sentindo toda universal. Apois, essa é a única universalidade que me interessa. Aí dou fé de dois tipos de escritos, uns que tentam forjar hegemonias universalizantes e alguns ligados às perspectivas decoloniais lidos como pessoais demais pelo academiquês. Os primeiros me levam logo pra ginástica teórica, quase um processo de emagrecimento, que faça minhas inquietações caberem dentro delas. Produz paralisia e quietude. Os segundos me abrem outro desespero que não o do pulo da janela, desespero de escrita: os dedos coçam, a cabeça fervilha, parece que algo tá se dando que não preciso deixar escapar sem escorrer pra palavra, ainda que palavra não dê conta - e não é pra isso que palavra foi feita, não foi feita pra dar conta de nada, dar conta foi o que o império fez desgraçadamente dela.

Eu aprendi a falar com muitas línguas, mas me disseram que eu só podia pensar em cisbranquês, que só se fosse cisbranquês é que era conhecimento. Então, na primeira escrita, meu texto oscila entre um escrito muito egóico cheio de romantização de si, quando trago relatos, e uma escrita muito da cabeçuda academiqueira, quando começo a desenvolver uma ideia. Acontece que desenvolver ideia, aqui, é deixar acontecer o que aprendi com as gente subhumanas, como as mulheres que me criaram, _s que me acolheram, as árvores em que subi - e que me ensinaram a cair - e as águas que me banharam.

Daí que tô há bem dizer três anos já agora num doutorado experimentando caminhos para essa escrita e toda vida que tenho uma ideia muito boa pra usar de dispositivo de linguagem num dura dois dias eu vejo que ela tá impregnada e a serviço do projeto de mundo e de conhecimento que eu digo que tô querendo destruir. É rapidim que eu vejo que tá a serviço da manutenção de estruturas hierárquicas de poder mais que de sua destruição. Fico pensando como invocar ess_s corp_s que eu chamo sem instrumentalizar nossas tramelas e não consigo mesmo dar liga. Mas aí foi por isso mesmo que agora eu me arremedei, e foi com a ajuda da pesquisa de Nat Ridimuin e seu texto de Fim de Mundo (2018) que eu descobri que se eu reaprender a pensar nas nossas línguas talvez eu pelo menos chegue mais perto de alguma coisa que escapula.

Então tem esse trabalho de aproximar a escrita dum timbre em que eu me reconheça, que eu veja o cearês do meu sertão. Mas como eu também não sou só ele, essa escrita experimenta uma ruma de timbre, que são 
os muitos desafinos que tecem a minha voz e também o coro que ela soma com as vozes que invoco aqui. É pra desmantelar essa agonia e para dar fé das relações que urgem nas encruzilhadas de fim de mundo. Aí eu falei das ferramentas deles ali em cima, né, eu tava pensando com Audre Lorde. Se ela conta pra gente que "As ferramentas do mestre nunca destruirão a casa-grande" (LORDE, 2019, p. 89), descubro que não vai ser por um respeito à norma culta da língua do colonizador, pela inteligibilidade plena, pela racionalidade, pela lógica, nem pelas epistemologias eurocentradas que forjaremos brechas para atravessar e escapulir.

Aí eu já escuto que não pode ser assim, que tem que ter o distanciamento crítico, ou a proximidade crítica, e fico me perguntando o que diabo é crítica. Pois eu acho que o risco da proximidade é o da romantização dos processos, da dita sobreimplicação. Agora, vem cá, quem inventou o romantismo não foram os europeus, os mesmo que inventaram o universalismo, o distanciamento e a impessoalidade? Devem ter inventado a crítica também. Apois, nossas categorias são outras. Quer dizer, aqui não tem categoria, tem guiança. Pois, nossas guianças são outras. E eu digo isso como quem pergunta quando, na história ocidental da produção acadêmica, da filosofia, da epistemologia, a risca que diz quem é sujeito e quem é objeto e a pá que cava um abismo entre os dois protegeram o conhecimento do romantismo. A aposta que faço é a de que a racionalidade e a romantização da ciência e do distanciamento tem sido forças pra mais encrustrada das romantizações: a da imparcialidade acadêmica, a do saber científico como coisa comprovada. E tem servido, que nem a gente aprendeu com Grada Kilomba (2019), pros regimes de autorização de fala e de escuta, pra legitimar quem pode falar e que boca deve ficar calada.

Pois agora eu quero é pegar tudo que me autoriza a falar e usar pra dizer o que não deve ser dito. Porque a gente escreve enquanto faz comida, escreve sentada na bacia, produz conhecimento fofocando de ressaca, fritando no meio da festa, na cama do pós-sexo. O trabalho dessa tese é todo dia e é o dia todim, entrando pela noite.

E como estamos tratando de uma tese, portanto mergulhad_s no campo acadêmico campo que se instaurou aqui como parte do processo colonizatório, impondo a supremacia da razão sobre os saberes invisíveis - preciso e escolho trazer conhecimentos de toda ordem e experiencias e causos de todo canto. Tudo aconteceu, tudo é importante, tudo é substrato parte de nossos saberes.

O trabalho a ser feito para habitar a academia em aliança com os saberes que evoco aqui não é só o de apreender e escrever. Na academia, quanto mais preparada estivermos, mais baixas serão nossas notas. Quanto mais prontas e amoladas estivermos para fazer o trabalho que viemos fazer, mais insuficiente seremos para quem avalia nossas escritas.

Semana passada uma das mulheres mais sabidas que já conheci tava contando no grupo de estudos que a filha tem lhe cobrado a finalização do doutorado. Dizia que até ela mesma, a filha, já era doutora e a mãe ainda não. A mulher, mãe, sabida, devolveu logo que não estava de doutorado terminado porque estava sustentando inclusive o fato de que a própria filha fosse doutora. Quando a escutei, eu, que estou aqui cumprindo os prazos da Capes e do programa de pós-graduação de que faço parte, finalizando um artigo para submeter em uma revista, e me ancoro em tudo que esta mulher sustenta, não pude deixar de interpelar a mim mesma a questão-fundamento: que academia é essa que estamos fazendo que contribui para que quem nos sustenta em tudo ainda não tenha seus devidos títulos?!

tenhamos coragem para transformar nossa língua cortada e navalha do tempo: Fazer novos compromissos, assentar o destino na esquina, sabendo que não há, aliás nunca houve, nesse mundo que se acaba, coisa nenhuma a perder (GUEDES, 2020, s/p).

Essa tese conjura o fim da academia como a conhecemos. Esse conjuro apocalíptico é um ato de cuidado. Um cuidado que não vai ser visto nem sentido por quem quer sustentar o terreno em que a supremacia da razão, da universalidade e do distanciamento crítico se adubam. Eu vim desde o latifúndio abrindo porteiras e derrubando cercas, varando cancela. E eles nem deram fé. "Porque a questão é que aquilo que estamos roubando de volta, aquilo que nos foi roubado, nunca pertenceu a ninguém. É o que compartilhamos." (MOTEN; HARNEY, 2020, s/p) 
Eu li Cíntia Guedes, Fred Moten e Stefano Harney e quis dizer que o terreno da academia não vai ruir pela metade, que a isso estamos atent_s e cuidados_s. Eu quis dizer que não tem só meio fim do mundo e isso invocamos, porque o que temos não é finito, não está para ser perdido. Quis dizer que não termos a perder é que o arame farpado que cerca o terreno da universidade e da produção de conhecimento não corta mais a gente e que nossos conhecimentos não cabem no seu produtivismo. Eu _s li, e senti que nossos saberes, que nunca estiveram perdidos, não estão mais para ser ganhados. Quis dizer que derrubar os muros da universidade e da academia, pra nós, nunca foi uma metáfora. Quis evocar que a gente, a gente cresce é por dentro, que não somos de ocupar, somos de invadir, e é sem dar conta. Eu _s li, e senti que nosso ato de cuidado, a erva que nos cura agora, já era daninha desgraçando o terreno da episteme. Senti que nós crescemos, broiamos, da sua terra arrasada, que sujeito e objeto não vai mais dá pé e que nós, nós só abrimos terreiro para a aliança.

Eu_s li, me invoquei com seus dizeres, quis evocar uma coletividade, mas fato é que não estou roubando nada de volta, que muito do que nunca pertenceu a ninguém sempre foi dito meu e que estou há pouco engatinhando nos gestos de partilha. Fato é que sempre tive a perder, e que embora agora eu sustente que o que tenho a perder não vale a pena ser sustentado, sigo sustentando ilusões e chorando as perdas. Eu fui designada à Universidade, desde meu nascimento. Eram muitos os livros em casa, foram muitas as escolas particulares e os cursinhos pré-vestibular. A academia sempre foi uma opção, dentre muitas, que com dezesseis anos, eu tava era digitando os textos dos autores europeus e latino-americanos da tese da minha mãe. Mas se a academia, para mim, é uma herança, sustentar que o que está para ser perdido não é fundamental, que não pagarei - e nem terceirizarei a dívida - o custo da universalidade, da racionalidade e do distanciamento crítico, é hackeá-la em aliança à minha vida e às vidas daquel_s que chamo minh_s. A academia sempre esteve à minha espera, mas eu já esperei muito para dizer-lhes que não estou aqui para servi-la. Meu serviço é o de outros saberes, e é este o rigor, a epistemologia e a metodologia com as quais escrevo.

E se esse nós, essa unidade da coletividade, ela não é para mim, desconfio que no fim da academia como a conhecemos, no fim do mundo como o conhecemos (SILVA, 2019), nas corpas em dissidência empesteando os terrenos, é que ela não será. E dar fé disso não é impeditivo para o desmoronamento dos cercos acadêmicos. É, sim, se reconhecer e se situar enquanto desmantelo, é abrir espaço e superfície de contato.

Não é na identidade, na representação, na massificação, nas suas categorias.

É nas fraturas e fissuras, todas, que esse edifício vai ruir.

E não vai sobrar eco sobre ego.

\section{Referências Bibliográficas}

ANZALDÚA, Glória. La conciencia de la mestiza/Rumo a uma nova consciência. Rev.

Estud. Feministas.,Florianópolis , v. 13, n. 3, p. 704-719, Dec. 2005.

GUEDES, Cíntia. A Coragem que não Temos. in: Outros Fins que Não a Morte. Mote e

Cereal Melodia (org). São Paulo, 2020.

HARNEY, Stefano; Moten, Fred. Quando Estamos Separados, Não Estamos Sozinhos. in:

Pandemia Crítica. São Paulo: N-1 Edições, 2020.

LORDE, Audre. Irmã Outsider: Ensaios e Conferências. Tradução de Stephanie Borges. Belo Horizonte: Autêntica, 2019.

MARTINS, Leda Maria. Performances do tempo espiralar. Performance, exílio, fronteiras: errâncias territoriais e textuais. Org. Grabriela Ravetti e Márcia Arbex. Belo Horizonte: Departamento de Letras Românicas, Faculdade de Letras/ UFMG: Poslit, 2002. Pp.14-45.

MOMBAÇA, Jota. A plantação cognitiva., São Paulo: Museu de Arte de São Paulo, Masp Afterall, 2020.

SILVA, Denise Ferreira da. A Dívida Impagável. São Paulo: Casa do Povo, 2019. 